\title{
Could there be a male commitment skepticism bias and a female sexual overperception bias? Novel hypotheses based on Error Management Theory
}

\author{
Laith Al-Shawaf ${ }^{1,2}$
}

Published online: 4 May 2016

(C) Springer International Publishing 2016

\begin{abstract}
Error management theory is an important and fruitful scientific theory. However, it might be useful to revisit the way we conceptualize the commitment skepticism bias and the sexual overperception bias to improve their consistency with the core logic of the theory. In this paper, I advance a novel view that allows for the possibility of a male commitment skepticism bias and a female sexual overperception bias. Discussion focuses on the new hypotheses this alternative conceptualization yields, the hidden assumptions it relies on, and the conceptual and empirical benefits it may offer.
\end{abstract}

Keywords Error management theory $\cdot$ Bias $\cdot$ Commitment skepticism $\cdot$ Sexual overperception $\cdot$ Father $\cdot$ Mother $\cdot$ Cost asymmetry

By all the relevant criteria, error management theory (Haselton and Buss 2000; Haselton and Nettle 2006) is an important and fruitful scientific theory: it is parsimonious, explains known phenomena, makes novel predictions, applies to many different content domains, and is undergirded by a compelling a priori logic. Nonetheless, we could reframe some of the hypotheses that fall under its umbrella - notably the sexual overperception bias and the commitment skepticism bias - to make them more consistent with the core logic of error management theory.

Laith Al-Shawaf

laith@bilkent.edu.tr

1 Department of Psychology, Bilkent University, Ankara, Turkey

2 College of Life Sciences, Wissenschaftskolleg zu Berlin (Institute for Advanced Study), Berlin, Germany
For example, the sexual overperception and commitment skepticism biases are often thought of as sex-specific: sexual overperception is regarded as a male bias, and commitment skepticism is regarded as a female bias (Haselton and Buss 2000; Cyrus, Schwarz, and Hassebrauck 2011; Henningsen and Henningsen 2010; Kunstman and Maner 2011). Some authors rightly draw attention to the importance of withinsex individual differences in these phenomena (e.g., Perilloux, Easton, and Buss 2012), and others have pointed out contexts in which the biases should be absent (Haselton and Buss 2000), but we nonetheless typically regard these biases as sex-specific. This is a useful approximation, but in this paper I will argue that it is ultimately not the most accurate way to conceptualize these phenomena.

A brief recap of these two biases may be helpful. The sexual overperception bias is thought of as a male tendency to overestimate women's sexual interest on the basis of ambiguous cues such as a friendly smile or direct eye contact. It is typically explained by appealing to the fact that ancestral males could have made two types of errors when assessing women's sexual interest: failing to detect real sexual interest, or mistakenly seeing sexual interest where there was none. Of these two errors, failing to detect real sexual interest was the much more costly error in terms of reproductive success, so selective pressures led to the evolution of an adaptively biased inferential mechanism that systematically overestimates women's degree of sexual interest (Haselton and Buss 2000; Haselton and Nettle 2006; but see also Perilloux and Kurzban 2015; Perilloux, Muñoz-Reyes, Turiegano, Kurzban, and Pita 2015).

The commitment skepticism bias, on the other hand, is thought of as a female tendency to underestimate men's commitment intent on the basis of ambiguous cues such as men's behavior or speech acts. This bias was predicted a priori according to the following logic: ancestral women could have made two types of errors when evaluating the sincerity of 
men's commitment intent: overestimating or underestimating men's commitment intent (Haselton and Buss 2000). Of these two errors, overestimating men's commitment intent was the much more costly error in terms of reproductive success (as it could have led to impregnation and abandonment, for example), so selective pressures drove the evolution of an adaptively biased inferential mechanism that systematically underestimates men's level of interest in commitment (Haselton and Buss 2000; Henningsen and Henningsen 2010).

\section{Should These Biases Be Regarded as Sex-Specific?}

The foregoing analysis is well-reasoned and compelling, and it led to the proposal of novel a priori predictions which were subsequently verified in empirical tests. These are the hallmarks of a good hypothesis. But we habitually conceptualize these as "male" and "female" biases, and this is not what the core logic of error management theory suggests. According to error management theory, what drives the evolution of decision-making biases or inferential biases is the ancestral cost-benefit matrix of the two types of error - not maleness or femaleness (Haselton and Buss 2000; Haselton and Nettle 2006). If we discover an ancestrally valid situation in which a male faces the typically "female" cost-benefit matrix in a commitment skepticism task, might we not expect the male to exhibit the commitment skepticism bias?

Here is an example: imagine that a woman is assessing her suitor's commitment intent. Suppose that her father is also assessing her suitor's commitment intent. What kind of costbenefit matrix does the father face in relation to the two types of errors he might make? He shares genes with his daughter, and his reproductive interests overlap considerably with hers. In fact, the cost-benefit matrix he faces is much more similar to the one that his daughter faces than it is to the one faced by a randomly selected male. If the suitor deceives and abandons his daughter, that outcome is bad for the father's reproductive interests, just as it is bad for his daughter's. And as with his daughter, that outcome is much more costly for him than the opposite error of underestimating the man's commitment intent and imposing a slightly longer waiting period before offering his parental stamp of approval. How should we expect the father to react, then? I propose that we should expect him to exhibit the commitment skepticism bias - despite the fact that this is usually characterized as a "female" bias. The key point is that it is not really the father's sex that is relevant; it is the cost-benefit matrix he faces in relation to the two types of errors. If he faces roughly the same matrix that his daughter faces, then we should expect him, like his daughter, to exhibit the commitment skepticism bias.

The same argument works for women and the sexual overperception bias. Imagine that a man is trying to determine whether a woman is interested in him. Imagine, too, that his mother is present and is also trying to guess whether the woman is interested in her son. As in the above example, the inferential task (and associated cost-benefit matrix) that the mother faces is similar to the one her son faces by virtue of their shared genes. If the mother fails to detect real interest in the woman, and thereby also fails to convey this apparent interest to her son, that is much more costly than if she mistakenly "detects" interest and needlessly tries to persuade her son to approach the woman. A missed sexual opportunity for her son is detrimental to her own reproductive interests for the same reason that it is detrimental to her son's: it is a missed opportunity to pass on her genes, too. And it is certainly more costly than the opposite error of erroneously detecting interest in the woman, and consequently wasting a bit of time and incurring some embarrassment by approaching the woman and getting rejected. The cost asymmetry may even be stronger for her than it is for her son: it is her son, not her, who might incur the negative reputational consequences of approaching the woman and getting rejected. Ultimately, this thought experiment highlights the same idea as the one about father and daughter: it is not sex or gender that predicts the expression of a bias, but rather the costs associated with the two types of error. If a man faces roughly the same cost asymmetry as his daughter, then we should expect him to exhibit the commitment skepticism bias. And if a woman faces roughly the same cost asymmetry as her son, then we should expect her to exhibit the sexual overperception bias. ${ }^{1}$

This is a novel way of conceptualizing the commitment skepticism and sexual overperception biases, but it should not be especially controversial. It follows from the central logic of error management theory, and I hope error management theorists will agree that it is more accurate and more consistent with EMT than our current conceptualization of the commitment skepticism bias as being fundamentally tied to femaleness and the sexual overperception bias as being fundamentally tied to maleness. It also leads to novel hypotheses, two of which are presented above (we could call them the skeptical dad and encouraging mom hypotheses).

More broadly and more importantly, this line of reasoning suggests that it may be possible to amplify, attenuate, erase, or even reverse error management biases by manipulating the cost-benefit matrices in strategic ways. Seminal error management theorists recognized the importance of this possibility when they predicted that males would not exhibit the sexual overperception bias when assessing their sisters' sexual interest in other men (Haselton and Buss 2000). Similarly, subsequent research has documented context effects that are capable of amplifying or attenuating the expression of EMT biases (Haselton and Galperin 2013), as well as individual difference and life history variables that predict the disappearance of an

\footnotetext{
${ }^{1}$ The focus of this paper is on fathers and mothers, but in principle the same argument applies to brothers and sisters.
} 
EMT bias (post-menopausal women do not exhibit the commitment skepticism bias; Cyrus, Schwarz, and Hassebrauck 2011). The current paper builds on this context-sensitive, facultative conceptualization of error management biases, proposing that the logic of EMT points to the possibility of a male commitment skepticism bias and a female sexual overperception bias. This is the first paper to make such a proposal.

\section{Two Assumptions}

The argument I have laid out in this paper relies on at least two hidden assumptions. I hinted at the first with the words "If we discover an ancestrally valid situation in which a male faces the typically 'female' cost-benefit matrix in a commitment skepticism task..." The situation has to be ancestrally valid: if mothers and fathers never influenced their sons' and daughters' mating decisions, then there would have been no selective pressure driving the evolution of such biases in the brains of mothers and fathers. The first assumption, then, is that ancestral mothers and fathers had some influence over their offspring's mating decisions. If this assumption is not met, then the argument does not hold, and neither do the hypotheses put forth in this paper. The evidence suggests that this assumption is plausible: in many societies ranging from modern industrialized societies to hunter-gatherer groups, parents do appear to influence their offspring's mating decisionssometimes quite forcefully (Apostolou 2007a, b, 2010a, b).

The second assumption has to do with the design of the computational mechanism that is responsible for producing the inferential bias. Knowing which cues it accepts as input may influence the hypotheses we generate. For example, modern contraception has freed women from the ancestral cost asymmetry involved in assessing a man's commitment intent. In the modern era, overestimating a man's commitment intent need no longer lead to reproductively detrimental outcomes such as impregnation and abandonment. This reduces, or even nullifies, the traditional cost asymmetry involved in assessing men's commitment intent. But this does not necessarily lead to the prediction that modern women will no longer exhibit the commitment skepticism bias (indeed, they still do; Cyrus et al. 2011; Haselton and Buss 2000; Henningsen and Henningsen 2010). Instead, whether or not women still express the bias depends on the design of the computational mechanism that produces the bias. If it is open to inputs such as hormonal birth control, then we may expect women on birth control not to exhibit the bias. But if the information-processing mechanism that produces the bias does not process inputs such as hormonal contraception, then the bias will still be expressed despite the fact that the cost asymmetry has disappeared. The key point is that if we want to amplify, attenuate, or erase biases, it may not be sufficient to simply manipulate the cost-benefit matrix of the two types of errors - we have to manipulate variables that the relevant information-processing mechanism actually accepts as input. If the relevant system does not process that input, then it may be possible for researchers to change the cost-benefit matrix without having any effect on the expression of the bias.

\section{Why Does This Matter?}

This shift in the way we conceptualize these two biases matters for a few reasons. First, it re-emphasizes the central importance of cost-benefit matrices in the evolution and expression of these biases. This is, after all, the core logic of EMT (Haselton and Buss 2000; Haselton and Nettle 2006), and the conceptualization advanced in this paper is more consistent with that logic than is the current way of thinking about the commitment skepticism bias and sexual overperception bias. Second, if this line of reasoning is correct, it reminds us that EMT biases may in principle be erased, reversed, or evoked in previously unexpected individuals or situations by strategically manipulating the costs associated with the two types of error (see also Haselton and Galperin 2013). Third, it yields novel hypotheses such as the skeptical dad and encouraging mom hypotheses. And finally, it is possible that researchers who adopt this theoretical lens-when revisiting existing biases or investigating new biases - may make novel theoretical or empirical findings that would have otherwise remained unexplored.

\section{Conclusion}

In this paper, I have suggested that it would be more accurate, and more consistent with the logic of error management theory, to reframe the way we think about the sexual overperception bias and the commitment skepticism bias. Instead of regarding them as male and female biases, it may be helpful to re-emphasize the fact that they are ultimately contingent on the costs and benefits of the two types of errors involved in their respective inferential tasks. This conceptualization allows for situations in which males may exhibit the commitment skepticism bias and females may exhibit the sexual overperception bias. It also yields two novel testable hypotheses to that effect.

Thinking about the sexual overperception and commitment skepticism biases as sex-specific is not completely off the mark, but it is not entirely accurate either. It is a close approximation and a useful shorthand, and it serves well in most instances. However, it nonetheless leads to the wrong predictions in certain instances, and may obscure certain discoveries from us by virtue of its unwarranted focus on maleness and femaleness. Given the logic of error management theory, it is 
also less theoretically accurate than the alternative proposed here. It may therefore be worthwhile to reframe the way we think about these biases. One way to start is by testing the novel hypotheses suggested in this paper and by bearing this alternative conceptualization in mind as we move forward to investigate new biases. Who knows - we may just reap some theoretical and empirical rewards as a result.

\section{References}

Apostolou, M. (2007a). Elements of parental choice: the evolution of parental preferences in relation to in-law selection. Evolutionary Psychology, 5(1), 70-83. doi:10.1177/147470490700500107.

Apostolou, M. (2007b). Sexual selection under parental choice: the role of parents in the evolution of human mating. Evolution and Human Behavior, 28(6), 403-409. doi:10.1016/j.evolhumbehav.2007.05. 007.

Apostolou, M. (2010a). Parental choice: what parents want in a son-inlaw and a daughter-in-law across 67 pre-industrial societies. British Journal of Psychology, 101(4), 695-704. doi:10.1348/ $000712609 x 480634$.

Apostolou, M. (2010b). Sexual selection under parental choice in agropastoral societies. Evolution and Human Behavior, 31(1), 3947. doi:10.1016/j.evolhumbehav.2009.06.010.

Cyrus, K., Schwarz, S., \& Hassebrauck, M. (2011). Systematic cognitive biases in courtship context: women's commitment-skepticism as a life-history strategy? Evolution and Human Behavior, 32(1), 13-20. doi:10.1016/j.evolhumbehav.2010.07.006.

Haselton, M. G., \& Buss, D. M. (2000). Error management theory: a new perspective on biases in cross-sex mind reading. Journal of Personality and Social Psychology, 78(1), 81-91. doi:10.1037/ 0022-3514.78.1.81.

Haselton, M.G. and Galperin, A. (2013) Error management in relationships. In Handbook of close relationships (Simpson, J.A. and Campbell, L., eds), pp. 234-254, Oxford University Press.

Haselton, M. G., \& Nettle, D. (2006). The paranoid optimist: an integrative evolutionary model of cognitive biases. Personality and Social Psychology Review, 10(1), 47-66. doi:10.1207/ s15327957pspr1001 3.

Henningsen, D. D., \& Henningsen, M. L. (2010). Testing error management theory: exploring the commitment skepticism bias and the sexual overperception bias. Human Communication Research, 36(4), 618-634. doi:10.1111/j.1468-2958.2010.01391.x.

Kunstman, J. W., \& Maner, J. K. (2011). Sexual overperception: power, mating motives, and biases in social judgment. Journal of Personality and Social Psychology, 100(2), 282-294. doi:10.1037/ a0021135.

Perilloux, C., Easton, J. A., \& Buss, D. M. (2012). The misperception of sexual interest. Psychological Science, 23(2), 146-151. doi:10. 1177/0956797611424162.

Perilloux, C., \& Kurzban, R. (2015). Do men overperceive women's sexual interest? Psychological Science, 26(1), 70-77. doi:10.1177/ 0956797614555727.

Perilloux, C., Muñoz-Reyes, J. A., Turiegano, E., Kurzban, R., \& Pita, M. (2015). Do (non-American) men overestimate women's sexual intentions? Evolutionary Psychological Science, 1(3), 150-154. doi: 10.1007/s40806-015-0017-5. 